\title{
David Machin and Paul Cobley* Ethical food packaging and designed encounters with distant and exotic others
}

https://doi.org/10.1515/sem-2019-0035

\begin{abstract}
There has been criticism of how Fair-Trade products represent workers in remote parts of the world where packaging offers an encounter with distant others which romanticizes and homogenizes them as a pre-modern form of ethnicity. Such workers are shown as always engaged in authentic, simple, honest decontextualized manual labor. And they are depicted as highly appreciative of, and empowered by, the act of ethical shopping. This paper shows that a close social semiotic analysis of Fair-Trade packaging reveals a different set of meanings which sit alongside the decontextualized ones. Designs integrate these workers into more contemporary kinds of modernist, rational, design chic, which communicates its own kind of honesty and authenticity. We consider how this, too, shapes how such consumers encounter distant others and its consequence for the meaning of the act of ethical shopping, where consumers can buy into moral alignment offered by products.
\end{abstract}

Keywords: Fair-Trade, social semiotics, packaging, authenticity, consumerism

\section{Introduction}

A number of scholars have questioned the very idea that we can challenge the global agri-food business through acts of shopping (Low and Davenport 2005), especially in a system where international regulation is specially designed to protect such international corporate activities (Fridell 2006) and where the countries providing Fair-Trade products can be battling the International Monetary Fund and World Bank Structural Adjustment Programmes (Low and Davenport 2005). And it has also been noted that over the past two decades, Fair-Trade has been assimilated by large food corporations as a marketing strategy (Geysmans et al. 2017), often leading to ambiguities in the claims actually being made by such labelling (Cliath 2007).

\footnotetext{
*Corresponding author: Paul Cobley, Faculty of Arts and Creative Industries, Middlesex University, The Burroughs, London NW4 4BT, United Kingdom of Great Britain and Northern Ireland, E-mail: P.Cobley@mdx.ac.uk

David Machin, School of International Studies, Zhejiang University, 866 Yuhangtang Rd, Hangzhou 310058, P.R. China, E-mail: david.machin@oru.se
} 
There has also been criticism of the how Fair-Trade marketing and packages represent poor workers from distant places like South America, Sub-Saharan Africa or South Asia. This relates to the romanticization both of this kind of labor and of the settings where it takes place, such that the labor becomes a mere performance of authenticity and honest manual work for the needs of the middle-class consumer (Varul 2008). Such workers also appear either appreciative or empowered by the shoppers' act of consumption, despite the massive global and local inequalities and injustices which characterize their positions (Ramamurthy 2012).

In this paper we show that carrying out a close social semiotic analysis of the food packaging used for Fair-Trade products reveals something else highly important in regard to how consumers engage with these distant others through acts of shopping. The point that we demonstrate relates to how these distant others become integrated and fused into chic contemporary package designs. In times of the mainstreaming of ethical shopping, when corporations, supermarkets, and restaurant chains colonize concepts like Fair-Trade (Doherty et al. 2013), package design becomes important in communicating the ideas and values involved in such acts of consumption in ways that align with those of the market groups which the packaging targets. Carrying out a close social semiotic analysis (Ledin and Machin 2018) of the color, typography, textures, materials and forms of Fair-Trade product packages, we show how the authenticity and honesty of the distant other is fused with another kind of more modern and urban authenticity and honesty. The poor distant other, along with color, typography, textures, materials, and forms, becomes simply one component in designs which speak to a specific marketing target group.

\section{Representing distant others for food marketing}

The representation of distant others on food packaging has been occurring since the early days of food marketing. Ramamurthy (2012) has documented some of the key changes in such representations. Late nineteenth-century packages would show scenes of colonial tea plantations where colonial Europeans would be depicted overseeing production of the activities of regimented and passive locals. One central message in such images, Ramamurthy (2012: 368) notes, is that there was a clear sense that "Africans and Asians were born to labor." In the 1920s, Ramamurthy observes, there was a shift in representations of labor. Actual production processes and work activities were no longer depicted. Instead, in depictions after this period, we find lone demure female 
workers with flowers in their hair, armed with baskets which appeared more appropriate for carrying flowers than for a harvest (Ramamurthy 2012: 373). The tea plants themselves appear as would a plant in a domestic garden. Such representations served to soften both labor and local cultures (Ramamurthy 2012: 369).

While such representations had disappeared by the 1990s, they returned on Fair-Trade-associated products in the form of the "happy smiling worker from the south" (Ramamurthy 2012: 367). Such marketing was, in one way, unique since, rather than concealing acts of labor and production on packaging, it was here advertised (Hudson and Hudson 2003: 419). That the workers smile tells us they are happy with their situation and helps create a relationship between the worker and the consumer, changing the nature of market relations (Bryant and Goodman 2004).

However, these representations of labor have been criticized for a number of reasons. In the first place, the representation of labor is romanticized. In one sense this is typical of much food marketing. For example, it is common to observe depictions of an expert blender seen working in a whisky distillery, or a family baker in the farm kitchen baking bread. In each of these cases, there may be the sense of the humble, simple and honest knowhow which endows products with family traditions from generations (Miller 2001). This is especially prevalent in so-called "artisan" products in the contemporary marketplace. In each case, the depicted labor bears little resemblance to the real-life arduous industrial process which leads to the products. This is very much the case for Fair-Trade, where labor is always represented as manual and as related to craft and artisanal skills. As Varul (2008) observes, in fact only certain kinds of products and services - those which can suggest this kind of honest, humble artisanal type labor - are actually suitable for Fair-Trade. This would include agricultural produce, baskets, carvings, hand-made jewelry, etc. Products or services hailing from mechanical or technology-based products or services would not work in this context. The honesty of such manual labor is also one key component of the discourse of Fair-Trade in regard to how it presents a contrast with the cynical and anonymous world of corporate agribusiness (Pollan 2006).

Varul suggests that such representations have consequences for the kinds of identities that are viable in the representation of Fair-Trade workers. Representations such as these are never associated with the intellect in regard to the skills and knowhow of farming or of running a business (Cleverdon and Kalisch 2000: 175). Rather they are "suffering, simple and benevolent" (Varul 2008: 661). As Scrase (2003: 458) suggests, this is how the consumer is offered an experience of authenticity and traditionalism that, in turn, symbolizes a 
rejection of the rationalized, anonymous corporate world. Such a notion of the authentic hardworking peasant aligns with the idea of the authentic "noble savage we see sold to tourists as part of the escape from modern life" (Potter 2010). Varul (2008) notes that the message simply would not be acceptable if it was clear that some of these workers earned enough to buy their house and to afford designer furnishings. He suggests that there is clearly an agenda of development on these packages - although not in a concrete way that suggests that the identities of the people depicted will ever change.

Ramamurthy (2012) also observes that these depictions of labor can also present the workers as neoliberal subjects, as they are seen in the context of their own self determination and assertiveness. Some smile out of photographs, comfortable and communicating agency which conceals the incredible structural odds against them. Varul (2008), too, sees the Fair-Trade semiotics as having a highly neoliberal essence in that the whole ethos, particularly in the sphere of consumption, rests not on the massive structural change that might be needed for fairness to reign in the domain of international food production and agribusiness, but on the idea of an accountable self who acts according to individual morals. As Ramamurthy (2012: 378) asserts, "When we consider the continued inequalities, the smile of these seemingly 'empowered' workers denies the unequal conditions that continue to permeate global trading relations, which are the opposite of fair."

A second criticism of the representations of labor on Fair-Trade food packaging relates to the settings of the labor which often takes place in stunning and idyllic landscapes (Varul 2008). We see mountain ranges and unspoiled open expanses of forest. The actual places where hard agricultural labor and trade take place are substituted for desirable travel and tourist destinations (Varul 2008: 661). Such representations, it has been observed, are typical of other kinds of specialist foods such as organic products which, too, often carry romantic pastoral imaginary in their packaging (Bildtgård 2009).

Varul (2008: 661) argues that these idyllic exotic settings play an important role in the representation of Fair-Trade since distance and remoteness are important. Fair-Trade in places proximate to European consumers - within Europe, for example - would not be acceptable or have the same resonance for targeted consumers. These remote places, far from the heart of modern life are key to how the discourses of "slowness," "wholeness" and "authenticity" are communicated. As Shugart (2015) observes, such values lie at the heart of organic and ethical foods, discourses geared to the middle-class consumer's desire to position themselves as moral agents who stand against corporatism. In the end, such labor is therefore rendered as a spectacle located in idyllic landscapes for the ethicallyoriented consumer (Bryant and Goodman 2004: 359). 
A final criticism of these representations of Fair-Trade workers regards the way they are homogenized and represented as being of the same order: as generic, authentic, distant others. Representations of people from a range of cultures, places and ethnicities have their differences obliterated. They become levelled out through their smiling performance of labor, the romantic landscapes and neoliberal agency. And their ethnicity seems to bear no relevance to their position; they stand for what Varul (2008: 668) calls "pre-modern ethnicity" rather than the current incarnation of ethnicity which is implicated so comprehensively in immigration, conflict, globalization and global capitalism. And in no instance is there ever any sense that the represented people have any values that might clash with those of the middle-class consumer (Shugart 2015).

In regard to these criticisms, it has been argued that these Fair-Trade products are less concerned with activism for equity in global business than making visible the people who putatively benefit from our consumer choices. As Dwyer and Jackson (2003) put it, the represented people form a kind of "ethnic chic" for the Western consumer. In fact, market research shows that few consumers really understand the complexities of what Fair-Trade actually means (Low and Davenport 2005). Indeed, what the term does mean has shifted as the market has become swamped by products carrying a range of ethical claims, some of which are less robust on closer inspection (Cliath 2007). Those goods which are cheaper can proceed to replace more expensive ones on the shelf, while ticking the box for consumers seeking proclamations of ethical principles (Hudson and Hudson 2003). Low and Davenport (2005: 494) discuss the "halo effects" and "clean washing" effects of Fair-Trade where there is clear commercial appropriation of ethical principles. This can involve ambiguous claims on packaging and in marketing but can also involve companies, such as supermarkets and café chains, using Fair-Trade as part of branding and attracting middle-class customers who will then pay out to buy other, non-Fair-Trade, products on offer as well (Équiterre cited in Carrigan et al. 2005: 500).

In what follows, we show how it is not only "slowness" and "authenticity" which is communicated on these Fair-Trade packages. A close analysis of food packaging - including attention to features such as shape, color, texture, form, and fonts, as well as the pictures they carry - offers insights on a matter less documented: the discourses used to frame how the consumers of Fair-Trade encounter and engage with the distant others described above. Part of this meaningfulness, as will be shown, comprises how these distant others become 'coded' into coherent designs that communicate chic, urban modernity. Rural, distant forms of authenticity become configured and transformed as they are integrated into highly modernistic notions of the authentic, of creativity and 
rational minimalistic urban design. These products form a branded space where the middle-classes can buy into moral standards.

\section{Theory and methods}

This paper takes a social semiotic approach (van Leeuwen 2005) to food packaging. Drawing on the work of Halliday (1978), this theory is based on the idea that all communication relies on systems of choices which can be seen to have social functions. The meanings of such choices have been established over time and reflect the socio-political times in which the choosing took place. These choices - such as words, phrases, tropes, colors, shapes of typeface - will be deployed when communicating in order to make a particular point. Social semiotics seeks to observe the details of instances of communication in order to reveal the kinds of ideas and values which are being communicated. It is assumed that all forms of communication, such as texts, advertisements, and food packaging, are carriers of the ideas and values that underpin how societies operate and manage themselves. It is through these that we share, distribute and encounter our ideas about what things mean. But, influenced by Marxism, social semiotics assumes that these instances of communication are never neutral but are loaded with the ideas which serve the interests of those who make them. Whereas this is true for all semiotic endeavor to a great extent, the social semiotic tradition has been particularly concerned with how instances of communication do not just reflect the imperatives of the specific communication situation but, more broadly, reproduce the social relations of (capitalist) production. Much of this reproduction involves standardization of semiotic resources (Luckmann 2009). Social semiotics is therefore a highly useful way to approach food packaging, since designers make choices at many levels, including color, textures and shapes, all in regard to the associations that these will carry for the target consumer group, how these can be repeated or standardized and, at the same time, further the long-term interests of capital (Ledin and Machin 2018).

Two other theoretical concepts are important to our analysis. The first of these is Norman Fairclough's (1992) notion of “technologization.” His argument is that towards the end of the twentieth century there was an increase in the pace and intensity of "commodification" or "marketization" throughout society, where all parts of social life became "organized in terms of production, distribution and consumption” (Fairclough 1992: 207). As part of this process, he also observes a shift in the use and control of language which he calls the "technologization of discourse." This refers to the increase in the control and shaping 
of language and other forms of communication also used in processes of commodification and marketization. This technologization leads to a standardization and codification of the resources of communication. We see its effects in the changes in detail and research put into commercial visual design and also in the use of associated phrasings (Cameron 2000).

Our second concept is that of "integrated design" or "new writing" (van Leeuwen 2008; Ledin and Machin 2018). These concepts suggest a shift from what was observed by Kress and Van Leeuwen (2001) in regard to communication becoming more "multimodal." Kress and van Leeuwen held that in communication the roles formerly assumed by writing were being taken over by other semiotic resources. The notions of "integrated design" and "new writing," however, emphasize the fact that what is at issue is not so much that different semiotic resources take over from written language; rather, there is an integration which changes the manner in which both written language and other semiotic resources are used. Central to this is the way that the kinds of causalities, identities and connections formerly established in running texts are now manufactured through combinations of chunks of text, bullet lists, images, graphics, colors and other semiotic resources. The huge advantage of this kind of communication is that it can be used to easily suppress, gloss over, or replace complexities and difficult issues, and thus contradictions can be elided (Ledin and Machin 2018). In regard to food packaging, this means simply that more attention is given to how the designs communicate as wholes, how the parts work together to communicate ideas.

The examples presented below have been chosen from a collection made over six months, including photographs taken in supermarkets and cafés. These examples allow us to draw out some features of how and what such packages communicate about distant others and how integrated design allows causalities and relationships to be represented, symbolized rather than described. In case of many of the figures, because we were not able to get permissions, we include sketches which are intended to help visualization of the analysis. Actual examples of the packages can be found by doing a web search.

\section{Analysis}

\subsection{Creative designs and integrating elements with color}

Figure 1 shows a Fair-Trade coffee package. It is dominated by the image of the worker engaged in manual labor, very much as accounted for in the academic 


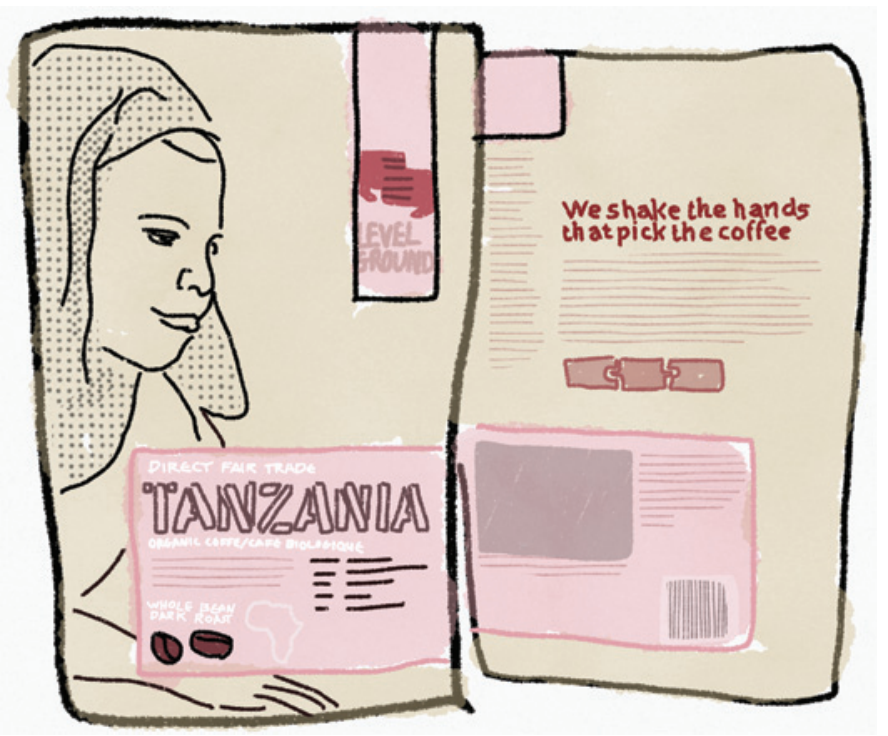

Figure 1: Direct Fair-Trade Coffee (Because we were unable to get permissions, we include a sketch which is intended to help visualization of the analysis. Actual examples of the package can be found by doing a web search).

literature reviewed above. The labor does not appear arduous but more oriented to the slower rhythms of craft, particularly in the way we see the worker sensuously touching the beans. This is our authentic, honest, simple, manual worker and distant other. What is important in this case is the way that the image, or the worker per se, is integrated into the design as a whole, which carries many other meanings.

We see that the image of the worker is slightly washed out and monochrome. Moreover, we can see that, particularly at the edges, the image takes on the beige color of the package as a whole. The color beige is often used for recycling bags and is a kind of neutral earthy color as well as indicating that no artificial dyes have been used in its production. Relatedly, the use of monochrome is also important here. According to Kress and van Leeuwen (2002), monochrome and the use of more restricted color palettes in design tends to signify more muted, measured moods in contrast to wider color palettes that can communicate fun, energy or diversity. Color on this package communicates something earthy and measured, therefore. Monochrome images have also often been used to suggest "timelessness." This is not an actual worker that we are invited to meet: it is the everyman of the symbolized 
timeless distant other. The washed out look of the images also reduces the details of the persons depicted and serves to idealize them (Machin 2007). For Kress and van Leeuwen (1996) such a scene can also be thought of as highly sensory, rather than realistic, due to the washed out look and reduction of details.

What is presented in the case of this image, therefore, is not a scene of labor, or a worker, that is documented for us but, instead, an image which invites the consumer to experience the sensory effect of a tasteful scene, integrated with a gentle sense of "earthiness." This is, of course, a scene which is abstracted from any real context. This kind of de-contextualization is an important part of the strategy by which images can more easily be coded into designs. As we see, the beige color is used for the logo "Level Ground," in the background for the text which explains "we shake the hands that pick the coffee," in the color of the graphic of Africa and for the graphic of the jigsaw puzzle pieces which show how the different parts of the trade process are put together.

What is important to consider are the other kinds of meanings color can be used for binding the workers. In the case of this design, the form of the package itself is important and differs from many typical supermarket coffee brands where the ground coffee is packed much more tightly in a box shape. Here we find new "innovative design," which has become more important as specialist brands need to work harder to distinguish themselves from mainstream brands or supermarket products which are colonizing the ethical shopping market (Goodman et al. 2011). The package here is flatter, able to stand upright on a base. It is broader at the top, making it slightly bucket shaped; it is also resealable. These new, innovative designs are also deliberately created to confer on the product meanings of "new stylish creativity" and "forward-looking ideas."

The materials used for this package are also important: a kind of paper known as paper-poly Kraft, made by woven polypropylene laminated paper. This design is used in place of the foil and paper of standard brands. Paper in packaging carries suggestions of "handmade" and "tradition" - for example in the case of a cheese that comes in crinkly paper rather than a sealed transparent plastic wrapper (Ledin and Machin 2018). Here the slightly rougher texture created by the weave structure is also important. Ledin and Machin (2018) note that smoother textures can connote an item that is polished or refined, whereas rougher textures can connote an object that is natural, unrefined or crafted rather than mass produced.

The fonts are also important to the ideas communicated by this package. We can see that there is an avoidance of more typical logo lettering as might be 
found on, say, Lavazza coffee. In Figure 1, we see that the most salient font is used to refer to the place "Tanzania," represented in the kind of characters used to mark crates and, in the process, creating a reference back to local processes of harvest and crating rather than to corporate activities of agribusiness or to the end processes of branding. Other fonts contribute different meanings. There is a more rounded font for the statement: "We shake the hands that pick the coffee." Such rounded fonts tend to be associated with emotions, feelings and nature as opposed to more angular fonts which are more associated with technology and rationality (van Leeuwen 2005). So, we find this statement presented in a more personal mood. Yet for the brand name 'Level Ground' and for the word "organic coffee” which sits under the word "Tanzania" we find more angular fonts. Here are meanings associated with the technical and rational. The words "Level" and "Ground" are also slightly different sizes which can suggest "creative" and "rebellious" as opposed to conformist situations where fonts for key phrases are all the same size (Machin 2007). Importantly, while the brand name takes the beige color and connotes Africa and the worker, the stylized shaking hands, with the beige "=" sign indicating the location of the exchange whereas "We shake the hands that pick the coffee" complements the color black in "Tanzania" and also the black in the worker's head scarf. The distant other is coded into all these different meanings carried in the design.

The iconography and written vocabulary found on these packages also play an important role and also need to be understood in the context of integrated design. We find the icon of the three pieces of a jigsaw to signify linking parts of the work, trade and the consumption process. What is linked here, the concrete details of the interaction and causalities, are not explained but, instead, symbolized. We also find the two minimalist, modernist stylized hands touching each other as a sign reinforcing all the other connotations of the connection between consumer and worker. But exactly what kind of contact this comprises is not explained, only symbolized. We might say that the identities of the different parties are communicated through the idealized worker, associated with the meanings of the icon for Africa and the muted earthy color plus the consumer who aligns with the design chic and the brand which presents itself as both emotional and rational and creative. What is also of note here is the brand's name, "Level Ground." Common to many of these ethical products is a typical branding play on words. In this case level ground suggests some kind of levelling out of the terrain of production trade and consumption which is also connoted in the symbolizing and the written reference to shaking hands. What this means may not necessarily be explained in explicit terms in the running text; 
rather, the main work of explication is conducted through icons of jigsaws, linking hands and fonts which communicate a more nebulous, as opposed to evidence-based, assertion of "care."

\subsection{Modernist, emotionally vibrant packages}

Figure 2 shows a slightly different typical form of Fair-Trade packaging. While many of the products by this company foreground pictures of workers in the usual fashion, or particularly emphasise idyllic landspaces, here they do not. This company provides coffee, but it also supplies a huge range of highly stylish coffeemaking machines for commercial and domestic use, along with cups and glasses.

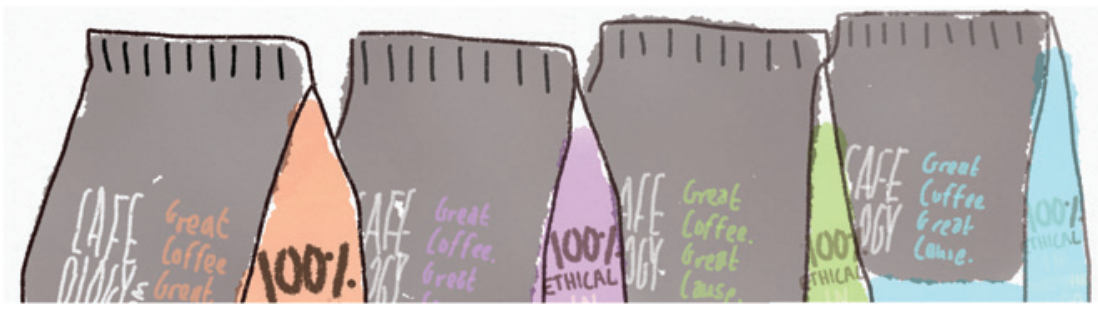

Figure 2: Emotional coffee packaging (Because we were unable to get permissions, we include a sketch which is intended to help visualization of the analysis. Actual examples of the package can be found by doing a web search).

In this case, we find a form of packaging that is newer to the market. Here we find a looser package design with only a plastic outer shell which has become fairly typical of organic and Fair-Trade packaging. There appears to be an association of "looser and relaxed" to "tighter and buttoned-up" vacuumpacked designs (Ledin and Machin 2018). Also of importance is that these packages change their form as they are handled, whereas the vacuum-packed coffees do not. This means that the consumer can interact with the form, creating greater engagement and also "relief." Whereas flat and even surfaces can suggest regulation and also processing, relief can communicate the opposite (Djonov and van Leeuwen 2011; Ledin and Machin 2018). This kind of packaging is therefore more suitable for a product which seeks to communicate lack of regulation or processing.

Here the material used for the packaging is biodegradable plastic which has a grained, textured feel, creating a sense of naturalness. This can be contrasted to high-end Italian-style coffees which might use smooth polished surfaces to 
suggest "refinement" and "sleekness." The use of color and typeface are also highly important in this packaging. As we see in Figure 2, the package for each individual variety of coffee carries a different color. These colors, while different in hue, are the same as regards levels of richness, brightness and purity. This allows them to rhyme and act together when seen on a shelf in a supermarket or specialist Fair-Trade outlet. Here, the wider palette across the range can communicate fun, energy or diversity. This is related to the carnival notion of diversity, habitually communicated by the clothing of the represented workers on Fair-Trade packages (Ramamurthy 2012). However, each individual package carries only one color along with black and white. In this way, as with the package in Figure 1, each has a limited palette and remains restrained and tasteful. Yet in each case optimisic emotional energy comes from the brightness and saturation.

What is crucial to the use of color on these designs, seen also in Figure 1, and Figure 3 below, is the use of flat panels of color. On the one hand, these

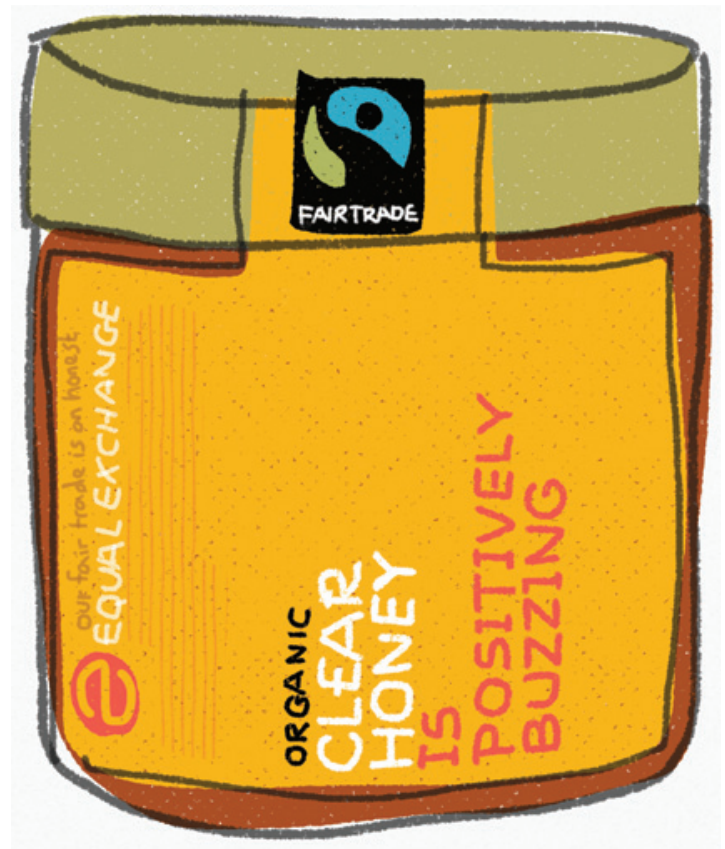

Figure 3: Honey pot (Because we were unable to get permissions, we include a sketch which is intended to help visualization of the analysis. Actual examples of the package can be found by doing a web search). 
empty spaces are used in design to create a sense of "room to think" or "room to breathe." Such designs can be contrasted, say, to designs for children which tend to be more crowded, where elements overlap. The emptier panels of color suggest stillness and simplicity. On the other hand, these panels of clean, flat color draw on the meanings of the use of color in modern art as in paintings by Mondrian (Kress and van Leeuwen 2002). We can see how this works, particularly when these packages with each variety carrying a different bright vibrant color, sit together on a shelf.

The fonts, looking at the side of the package in Figure 2, are of a range of heights and widths, associated in design with fun or being creative (Machin 2007). On the front of the design there is the stylised irregularity of a rather personalised "hand-written" type. Here, it is uneven and of different thicknesses, in a form which connotes "spontaneity" and "creativity." These ideas are also found in the way the edges of the text are slightly ragged. This creativity in the fonts is balanced by integration and unity created in the use of color coordination across the design where the writing on each panel takes color from the other panel.

In the case of this brand of coffee, the encounter with the other is one loaded in the first place with chic design. It is also coded through fonts which communicate a creative and non-conformist bearing. Here lies a sense of the discourses which challenge the inauthenticity and the impersonal nature of global corporate agribusiness. The modern minimal designs bring rationality, modernity and simplicity. Such references to artistic styles can themselves carry romantic notions of the creative soul. In modernist art we find the stripped-back look, such as the forms of Mondrian and this, too, can suggest a kind of authenticity. As we see in one of the following examples, such brands may even recruit up-and-coming artists to produce their whimsical impressionist, modernist and abstract art designs.

As with the package in Figure 1 we also find the use of language in branding and straplines. Here we find the slogans "Great Coffee, Great Cause" and " $100 \%$ ethical in everything we do." As with the previous example, these are integrated into the design, into the meanings carried by materials, textures, colors and fonts. Great Coffee, Great Cause is written in creative informal writing. It takes the color and texture from other parts of their design. The meaning of what the "cause" is here must in part be understood through how it is communicated in the design. Just as the tea packages described by Ramamurthy earlier in this paper showed how images of demure women feminise and soften labor, these designs fuse ethical action and chic design creativity into the meaning of this process. 


\subsection{Fair-Trade and industrial minimalism}

In the next example we also find that innovative design is a key feature of how Fair-Trade is communicated, which is also a common feature across organic and vegan products, for example. In Figure 3, we see a design which shares qualities with many brands of Fair-Trade and organic honey packaging which we have in our collection. In supermarkets standard brands of honey tend to be found packaged in a curved glass jar, with a metal lid which sits above a kind of "neck" or narrower section to the top of the glass. Often there is an image of a bee or some flowers. The jar allows the consumer to see the honey. The jar in Figure 3 is different. There are no curves in the shape as it takes the form of a straight-sided, squat, cylinder. Here the straight lines point to order and rationality rather than to the emotions or naturalness or expressiveness, of the curves of the traditional jar. This design certainly does not communicate "home made" or "farmhouse." The squat cylinder also gives a sense of stability and groundedness rather than a more elborately-shaped curved jar, thus connoting utility and lack of pretentiousness. Significantly, there is a plastic, rather than the metal, lid. Here the material helps to communicate a sense of lightness, but also connotates something modern rather than the more traditional metal and glass.

What is also special about the design in Figure 3 is the quantity of the surface area of the jar taken up by the label. On mainstream brands of honey, the label usually takes the form of a smaller panel, often oval in shape. Smaller labels can be used to take advantage of the affordances of glass as a material which can be used to display the contents. This transparency can constitute an "honesty" device. Other products, such as organic muesli, may have a plastic window in the card package where the product can be seen to carry out the same role, demonstrating that the contents are solid or have not dissipated. In the jar in Figure 3, however, the affordance of glass has not been used in this way since the label takes up a great deal of the surface. The product can only be seen at its edges. This contributes to the effect of the appearance of the squat, rational, cylinder.

The label itself also carries important meanings. There is much empty space and, again, we find panels of empty flat color communicating simplicity, minimalism and rationality. The color which the label carries, while communicating the ideas of the product itself, adds values of brightness and optimism; yet, at the same time, this is measured and restrained through the limited color palette and the quiet cleanness of the emptiness of the space. The fonts on the label are also typical of highly modern font styles (Machin and Polzer 2015), combining curvature, with angularity. The ragged right justification of the words creates a sense of informality and creativity which is also heightened by the use of different colors and sizes for the fonts. The paper in the label has the gentle 
grainy texture which seems obligatory for this kind of Fair-Trade, organic or raw product. Although, here, importantly, the relief is even, so the texture is quite smooth. This is important to avoid the connotations of those more rustic types of organic products which avoid references to modernity. Although we may find Fair-Trade packages which carry such rougher textures, they also use the meanings afforded by the flat empty spaces and angular technical typeface.

In the case of this honey packaging, to a large extent the authentic honesty of the manual labor is not present. Nor is the appreciative worker. Yet there is authenticity and honesty in the simplicity of the industrial minimalism of the grounded, emotionless design. Its creative connotations and empty space point to the alternative viewpoint of modern art. Fair-Trade, here is coded into this aesthetic, all of which positions its meaning in juxtaposition to the impersonal, the lack of creativity of corporate agribusiness.

\subsection{Technologizing ethnic diversity}

In Figure 4, we find many of the design themes observed in the previous examples. There is use of saturated colors to present the product range in a

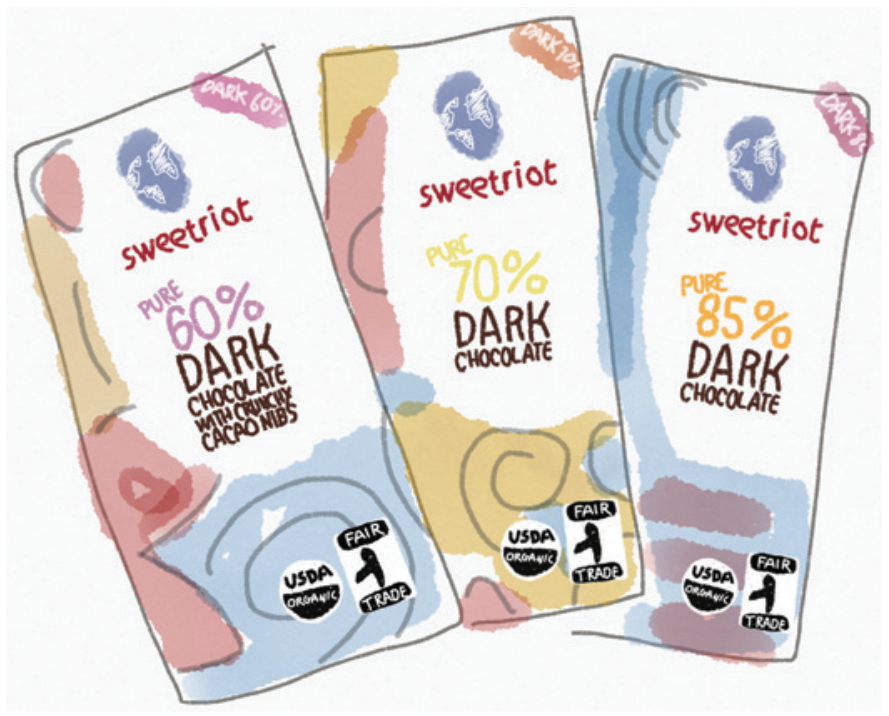

Figure 4: Chocolate packaging (Because we were unable to get permissions, we include a sketch which is intended to help visualization of the analysis. Actual examples of the package can be found by doing a web search). 
lively fashion akin to that used with the coffees, above. What is of interest here is that patterns used for the background of the designs reference what Varul (2008) labels homogenous ethic culture - items that are immediately recognizable as connoting ethnicity. Yet, looking more closely, the pattern chosen also appears to be influenced by the style of post-impressionism. On many Fair-Trade and organic packages aimed at different consumer groups, attempts to invoke ethnicity, or even designs that suggest children's drawings, also resemble chic art forms such as the paintings of Renoir, Gauguin or Van Gogh. Such a strategy domesticates other ethnicities, flattening them out into something entirely in harmony with middle-class western values. In addition, however, such designs foster associations of romantic creativity and self-expression which can signal a contrast with the corporate and the industrial. Here, the designs are able to fuse the authenticity of the "ethnic" print and its craft associations with the meanings of modern or romantic Impressionism.

We see on the designs in Figure 4 that the color used for the fonts on the different products is taken from the background color in the patterns, allowing the design greater integration. We also find the use of empty space in the white area where the brand name sits, again spacious, clean and simple. One contrasting use of color is in the band of quality which we see at the top right corner of each package, where we also find the more saturated glossy color used in traditional chocolate packages as markers of luxury and fineness.

We also see the font qualities and alignments used as in earlier examples. Those used for "Sweet riot" are uneven, again used to signal "creative," "nonconformity," or "irregularity." These fonts are highly contemporary, with their round form and flourishes (Machin and Polzer 2015) often created specifically to suggest openness and engagement. The fonts below, describing the chocolate, are angular and we find a repeat of the stencil-look from the kind of characters used to mark crates (see Figure 1, above). We also see other icons in this same style in the form of the stenciled planet earth design towards the top of the package. The word "Pure" and the information on the calorie content also have this stamped look and sit slightly out of alignment with the other text as if they are spontaneous. As with the previous designs, the distant other, with whom the product is linked and branded, is encountered through a chic version of homogenized ethnic art, the latter of which is again coded into elements of design which recall modernity.

The naming of this product as "Sweet Riot" is also of note here. We have the play on words for the taste of the chocolate combined with the word "riot" which connotes some kind of disharmony or social upheaval. This package integrates this playful sense of social action and creativity/non-conformity with the marker of homogenized ethnicity fused with softer contemporary chic art forms. But as 
with the previous examples, exact causalities and consequences are represented as abstractions through the various elements and features of the designs.

\subsection{Integrated design coded into places of consumption}

Many of the kinds of packages we have considered in this paper so far can also be understood in regard to the commercial outlets where customers are specifically encouraged to consume them. Indeed, this is an integral part of the process of considering how these distant others are brought into the everyday environment of consumption.

Figure 5 shows a serving area from a Starbucks café. We can see the images of the Fairtrade workers behind the serving counter. We see rows of hands carrying out labor, a woman holding an unfinished woven basket looks out at us. The images show different activities, yet are coded in the same monochrome look. While Starbucks is one of the more mainstream outlets to embrace Fair-trade, others are becoming more specialized in Fair-Trade products. Some of these, like the chain Johan \& Nyström, in the city near where one of the authors lives, as well as having cafés and selling a range of coffee, sell a range of highly chic coffee-making and serving equipment, including cups and plates. Fair-Trade, here, can be thought of as having halo or a cleansing effect the rest of their products.

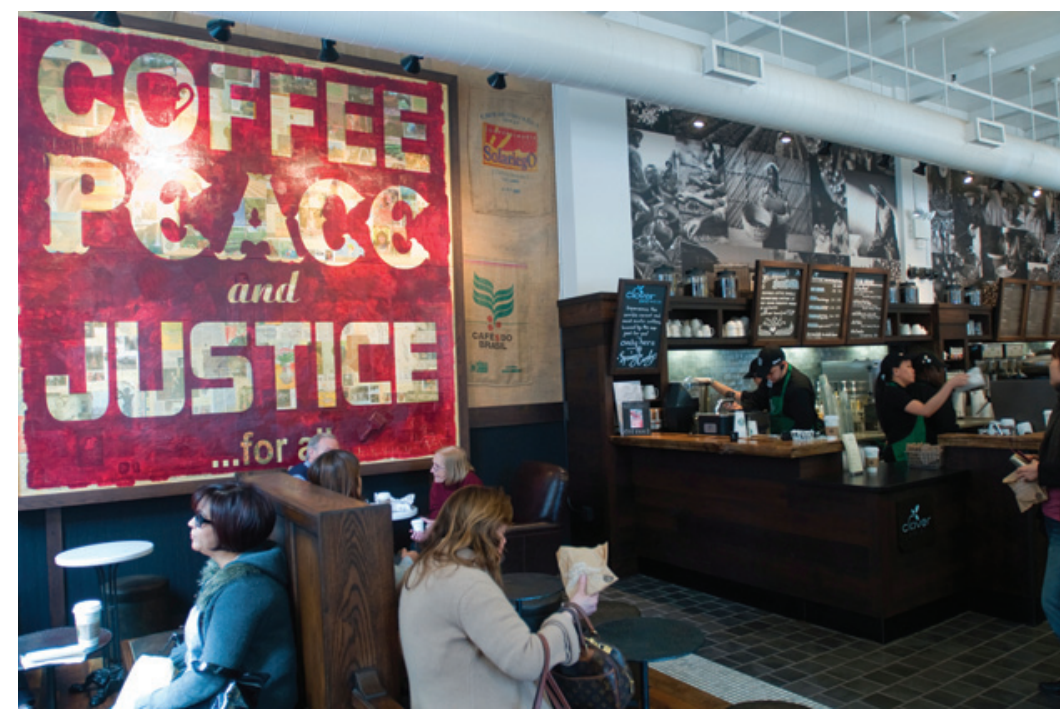

Figure 5: Starbucks café showing Fair-Trade photographs (Alamy Images). 
What is of specific interest for us in this paper is how such cafés themselves become sites of consumer encounters with distant others. Coles et al. (2011) and Goodman et al. (2011) have shown how such retail outlets must now work harder to distinguish themselves from other "ethical" outlets since Fair-Trade has become more widespread. They suggest that the professional, middle-class consumer is unlikely to be attracted either by "hippie" associations or by direct broadcast of Fair-Trade information. In this context, as we have seen though the analysis of the packaging in this paper, the distant other and the notion of ethical consumption amount to a coding of design choices which relate to modern creative thinking as well as to authenticity.

In addition to displaying Fair-Trade products, many of these cafés will contain perhaps one, or two, large prints of smiling workers in monochrome photographs mounted on the wall - as we see in Figure 5. Sometimes, the prints will have a slightly textured "natural" surface. The depiction may take the form simply of dark-skinned hands in close-up, holding coffee beans (Geysmans et al. 2017). There may be a few words about the workers and the company's relationship to them. Starbucks has the large banner declaring "Coffee peace and justice for all." Yet such images will be cleanly integrated into the design of the café as a whole in a manner germane to much of what has been discussed in this paper.

Looking at the café shown in Figure 5, one can see typical features of contemporary, chic, city-center coffee shops. Cues to "authenticity" and the "natural" are evident in the wood used for the counter, which is slightly rough-textured and has some relief. The color of this wood is coordinated with other hues used for the wooden floor, tables and paint work. There is the tiled wall. In some cafés these may even be given a worn look, or it is possible to find a bare brick. In each case there is a sense of provenance, of a former era of labor, certainly some air of the pre-corporate. Here this kind of authenticity and provenance can be integrated with the authenticity of peasant labor. The same is true of the alignment of the honesty of industrial labor with that of the agricultural laborer. But just as the labor we see on the packages is romanticized and decontextualized, so is that of the industrial past. Yet, in both cases, what we encounter are selected features and elements of these times and contexts, removed and stripped back and coded to be used more easily in these integrated designs.

The photograph of the dark hands holding some beans will be coordinated with the colors and materials of the shelving and lighting; there may also be some bare steel for a stripped back industrial chic, coordinating, too, with the colors and texture of the retro menus which may contain some exotic ingredients such as chia or amaranth. In the above scene, we see the use of a muted, measured color scheme for the retro look. White and black are used to link 
different elements in the setting. In such cafés, Fair-Trade and organic products sit in tidy rows, where the bright saturated colors now complement each other and add touches of emotion and energy with the otherwise more reserved colors. Additionally, the face of the distant other may be seen amongst them, coded into Mondrian-style designs, smiling as they sensually touch leaves or coffee beans.

\section{Conclusion}

One criticism of Fair-Trade has been that "ethical consumerism" is highly individualized, involving the lone shopper supposedly challenging the structures and institutions of global capitalism (Seyfang 2004). Moreover, although still relatively small, Fair-Trade has become colonized by this mainstream capitalism and characterized by a vast range of shades and less transparent forms often used for different degrees of "clean washing." This sits alongside research which shows that, in fact, consumers have little understanding of Fair-Trade processes and also tend to make shopping decisions on the basis of taste (Low and Davenport 2005). Looking at the semiotics of Fair-Trade products and outlets, we find that this individual ethical shopping act does not foreground the concrete issues at the core of Fair-Trade, nor does it remedy the iniquities that give rise to the Fair-Trade initiative in the first place. We find the neoliberal peasant workers happy because they are able to take control over their own lives, comfortably conveying to the consumer how they embody all that is opposed to the corporate world with their honest and authentic manual labor. We also find indications of ideas and values in design which relate to fashionable and intellectual forms of chic modern design and creativity. The peasant and the problems of unequal global trade and global agribusiness are woven into, but simultaneously occluded from, these creative designs. Causalities and relationships between the worker, company and consumer are symbolized in graphics, colors, fonts, textures, forms and materials. It may be clear that consumers would not buy Fair-Trade products more associated with "hippie"-type alternative culture. Therefore, all social causes may indeed require this kind of coding to ensure that it communicates ethical behavior in a way that aligns with chic taste and style rather than with justice or struggle. Yet it also means that actual causes, processes and social relations are suppressed. A daily Americano in the high street outlet where we stop to send and collect email may not help raise the profile of the realities of the devastation caused to the country where that coffee is produced, particularly the structural adjustment programs imposed by global organizations which result from a long history of exploitation. 


\section{References}

Bildtgård, Torbjörn. 2009. Mental foodscapes: Where Swedes would go to eat well (and places they would avoid). Food Culture and Society 12(4). 498-523.

Bryant, Raymond \& Michael Goodman. 2004. Consuming narratives: The political ecology of "alternative" consumption. Transactions of the Institute of British Geographers 29. 344-366.

Cameron, Deborah. 2000. Good to talk?: Living and working in a communication culture. London: Sage.

Carrigan, Marylyn, Svetla Marinova \& Isabelle Szmigin. 2005. Ethics and international marketing: Research background and challenges. International Marketing Review 22(5). 481-493.

Cleverdon, Robert \& Angela Kalisch. 2000. Fair-Trade in tourism. International Journal of Tourism Research 2.171-187.

Cliath, Alison G. 2007. Seeing shades: Ecological and socially just labeling. Organization and Environment 20(4). 413-439.

Coles, Benjamin \& Crang, Philip. 2011. Placing alternative consumption: Commodity fetishism in borough fine foods market, London. In Tania Lewis and Emily Potter (eds.), Ethical consumption: A critical introduction, 87-102. London: Routledge.

Djonov, Emelia \& Theo van Leeuwen. 2011. The semiotics of texture: From haptic to visual. Visual Communication 10(4). 541-564.

Doherty, Bob, Ian Davies \& Sophi Tranchell. 2013. Where now for Fair-Trade? Business history 55(2). 161-189.

Dwyer, Claire \& Peter Jackson. 2003. Commodifying difference: Selling EASTern fashion. Environment and Planning D: Society \& Space 21(3). 269-291.

Fairclough, Norman. 1992. Discourse and social change. Cambridge: Polity.

Fridell, Gavin. 2006. Fair-Trade and neoliberalism. Latin American perspectives 33(6). 8-28.

Geysmans, Robbe, Michiel P. M. M. De Krom \& Lesley Hustinx. 2017. “Fairtradization”: A performative perspective on fair trade markets and the role of retail settings in their enactment. Consumption Markets \& Culture 20(6). 539-558.

Goodman, David, Melanie Dupuis \& Michael Goodman. 2011. Alternative food networks: Knowledge, practice, and politics. Abingdon: Routledge.

Halliday, Michael A. K. 1978. Language as social semiotic: The social interpretation of language and meaning. London: Edward Arnold.

Hudson, Ian \& Mark Hudson. 2003. Removing the veil? Commodity fetishism, Fair-Trade, and the environment. Organization \& environment 16(4). 413-430.

Kress, Gunther \& Theo van Leeuwen. 2001. Multimodal discourse: The modes and media of contemporary communication. London: Arnold.

Kress, Gunther \& Theo van Leeuwen. 2002. Color as a semiotic mode: Notes for a grammar of color. Visual Communication 1(3). 343-368.

Kress, Gunther \& Theo van Leeuwen. 1996. Reading images: The grammar of visual design. London: Routledge.

Ledin, Per \& David Machin. 2018. Doing visual analysis. London: Sage.

Low, Will \& Eileen Davenport. 2005. Has the medium (roast) become the message?: The ethics of marketing Fair-Trade in the mainstream. International Marketing Review 22(5). 494-511.

Luckmann, Thomas. 2009. Observations on the structure and function of communicative genres. Semiotica 173(1/2). 267-282. 
Machin, David. 2007. Introduction to multimodal analysis. London: Bloomsbury.

Machin, David \& Lydia Polzer. 2015. Visual journalism. London: Palgrave.

Miller, Daniel. 2001. The poverty of morality. Journal of Consumer Culture 1(2). 225-243.

Pollan, Michael. 2006. Mass natural. New York Times Magazine (4 June 15). https://www. nytimes.com/2006/06/04/magazine/04wwln_lede.html (accessed 2 December 2019).

Potter, Andrew. 2010. The authenticity hoax. London: Harper.

Ramamurthy, Anandi. 2012. Absences and silences: The representation of the tea picker in colonial and Fair Trade advertising. Visual culture in Britain 13(3). 367-381.

Scrase, Timothy J. 2003. Precarious production: Globalisation and artisan labor in the Third World. Third world quarterly 24(3). 449-461.

Seyfang, Gill. 2004. Consuming values and contested cultures: A critical analysis of the UK strategy for sustainable consumption and production. Review of social economy 62(3). 323-338.

Shugart, Helene A. 2015. Food fixations: Reconfiguring class in contemporary US food discourse. Food Culture \& Society 17(2). 261-281.

van Leeuwen, Theo. 2005. Introduction to social semiotics. London: Routledge.

van Leeuwen, Theo. 2008. New forms of writing, new visual competencies. Visual Studies 23(2). 130-135.

Varul, Mattias Z. 2008. Consuming the campesino: Fair-Trade marketing between recognition and romantic commodification. Cultural Studies 22(5). 654-679.

West, Patrick. 2004. Conspicuous compassion. London: Civitas. 